\title{
A Correlational Study to assess the Level of Anxiety and Social Media Exposure during COVID Outbreak Among Middle Aged Adults in Selected Area at
} Tirupati

\author{
K. Sudha Blessy ${ }^{1}$, T. N. Prasanna Lakshmi², Dr. M. Bhagya Lakshmi ${ }^{3}$, Dr. S. Hemalatha ${ }^{4}$ \\ ${ }^{1,2} \mathrm{MSc}$ Nursing, College of Nursing, Sri Venkateswara Institute of Medical Sciences (SVIMS) University, \\ Tirupati, Andhra Pradesh, India \\ ${ }^{3,4}$ Assistant Professor, College of Nursing, Sri Venkateswara Institute of Medical Sciences (SVIMS) University, \\ Tirupati, Andhra Pradesh, India
}

\begin{abstract}
Article Info
Volume 8, Issue 1

Page Number: 121-128

Publication Issue:

January-February-2021
\end{abstract}

\section{Article History}

Accepted: 21 Jan 2021

Published: 30 Jan 2021

\section{ABSTRACT}

The outbreak of COVID-19 in China has affected the lives of many. It has not only affected the people economically/ professionally but even mentally and emotionally. Level of anxiety and its association with social media exposure among middle-aged adults was assessed during this outbreak, there was excess use of social media which can increase the anxiety. Objectives of the study were: To assess the levels of anxiety and social media exposure, to identify the co-relation between levels of anxiety and social media exposure and to associate the levels of anxiety and the social media exposure with selected demographic variables during COVID outbreak among middle aged adults. A correlational study design was employed on 35 middle aged adults at rural area of Tirupati by using Nonprobability Convenient Sampling technique. The level of anxiety was assessed using a standard GAD-7 scale and social media exposure was assessed by using a structured questionnaire. The results were out of 35 sample $11.40 \%$ had mild anxiety, $40 \%$ had moderate anxiety, $42.90 \%$ had moderate severe anxiety and $5.70 \%$ had severe anxiety $(31.9 \pm 3.03)$ and $91.40 \%$ had average social media exposure and $8.60 \%$ had above average social media exposure (10.2 \pm 3.54$)$. Based on the obtained findings this study demonstrated that there is moderate positive correlation between the level of anxiety and social media exposure. There is correlation between the level of anxiety and social media exposure with the demographic variables. There is significant association between the health status with level of anxiety and with social media exposure at $\mathrm{p}<0.05$ level.

Keywords : COVID-19 Outbreak, Social Media Exposure, Level of Anxiety 


\section{INTRODUCTION}

The World Health Organization has declared the coronavirus disease 2019 (COVID-19) a pandemic. On 31 December 2019, a cluster of cases of pneumonia of unknown cause, in the city of Wuhan, Hubei province in China. ${ }^{3}$ In India, total cases recorded were 9.9 million and in Andhra Pradesh 876000. Currently, all of us are experiencing thoughts, and situations we have never experienced before. The outbreak of COVID has caused mental health problems among the public. Adults already have many issues and anxiety, and the symptoms get increased more in these situations where the official departments strive to improve the public's awareness of prevention and intervention strategies by providing daily updates about surveillance and active cases on websites and social media. WHO pointed out that identifying the underlying drivers of fear, anxiety, stigma that fuel misinformation and rumor, particularly through social media. Among middleaged adults the symptoms of anxiety being prevailed because of many conditions like lockdown leading to unemployment, financial crisis mainly by the social media exposure. ${ }^{1}$ Junling Gao's ${ }^{3}$ study findings suggest that there is high prevalence of mental health problems, which positively associated with frequent social media exposure during the COVID outbreak. These findings implicated the government need to pay more attention on mental health problems, especially depression and anxiety among general population and combating with "infodemic" while combating during public health emergency. HongJuan Jiang's ${ }^{8}$ study indicated that in-directed exposure to mass trauma through the media can increase the initial rates of post-traumatic stress disorder symptoms. But there was no study to examine the association between social media exposure and mental health problems among middle aged adults specifically. So, the current study aims to examine the association between the anxiety levels and the social media exposure during COVID outbreak by rapid assessment among the middle-aged adults.

\section{METHODS AND MATERIAL}

RESEARCH APPROACH: Quantitative Nonexperimental research approach was adopted which is most appropriate in the field of education for its practicability in real life situations. It has the advantage of feasibility and to some extent generalization. ${ }^{4}$

RESEARCH DESIGN: Correlational research design was selected to examine the relationship between anxiety and social media exposure during COVID outbreak. ${ }^{5}$ 


\section{VARIABLES OF THE STUDY:}

INDEPENDENT VARIABLE: Social media exposure during COVID outbreak, Age, Gender, Educational Status, Occupation, Type of family and Health Status DEPENDENT VARIABLE: Level of Anxiety

\section{SETTING OF THE STUDY}

The study was conducted in Nennuru, Ramachandrapuram, rural area of Tirupati. The setting was chosen based on researcher's feasibility in terms of availability and cooperation of required sample. The investigators were familiar with the setting and language of middle-aged adults in that area.

\section{POPULATION}

The population chosen for this study was the middleaged adults who are falling under the inclusion criteria.

\section{SAMPLE}

Middle aged adults aging from $45-60$ years of age beyond young adulthood but before the onset of old age.

\section{SAMPLE SIZE}

Sample size consists of 35 middle-aged adults who are falling under the inclusion criteria.

\section{SAMPLING TECHNIQUE}

Non-Probability Convenience Sampling Technique was adopted to select the sample randomly.

\section{CRITERIA FOR SAMPLE SELECTION:}

a) Inclusion Criteria:

- Middle-aged adults who are available in the area selected during the time of study

- Cooperative to participate in the study

- Middle aged adults exposed to social media like watching news from TV, WhatsApp, YouTube for more than 3-5 hours.

- Middle adults aged 45-60 years

b) Exclusion Criteria: Who are

- not interested and not co-operative

- not understanding Telugu and English

- $\quad$ not exposed to social media

\section{DEVELOPMENT AND DESCRIPTION OF THE} TOOL:

The tool was developed with the help of related literatures from journals, websites, discussions, and guidance from experts.

The tool consists of 3 sections: 
Section-I: It consists of details on demographic data, such as age, gender, education, occupation, type of family and health status.

Section-II It consists of total questions of 15 where each question carries the scoring from 0-4 based on the exposure time and effect.

Scoring Interpretation:

0-20 $\rightarrow$ Below Average

21-40 $\rightarrow$ Average

41-60 $\rightarrow$ Above Average

Section-III: A generalized anxiety disorder scale-7 (GAD-7) is a 7- item, self-rated scale developed by Spitzer and colleagues (2006) as a screening tool and severity indicator of GAD. It consists of 7 items.

Scoring Interpretation: Each question has four options (Not at all, Several days, More than half the days, Nearly every day) with scoring $0-3$. Higher the score indicates severe anxiety, lower the score indicates mild anxiety.

\section{PROCEDURE FOR DATA COLLECTION}

Prior permission was taken from the Village Secretary, Nennuru, Ramachandrapuram, rural area of Tirupati to conduct the study. Samples of 35 middle-aged adults were selected. A brief introduction of researchers and the purpose of the study was explained, consent was obtained from participants.

\section{RESULTS}

\section{SECTION-I}

Table-1. Frequency and percentage distribution of demographic variables among middle aged adults. $(\mathrm{n}=35)$

\begin{tabular}{|c|c|c|c|}
\hline \multicolumn{2}{|c|}{$\begin{array}{c}\text { Demographic Variables } \\
n=35\end{array}$} & $\begin{array}{l}\text { Frequency } \\
\text { (f) }\end{array}$ & $\begin{array}{c}\text { Percentage } \\
(\%)\end{array}$ \\
\hline \multirow[t]{4}{*}{ Age in years } & $45-48$ years & 10 & 28.6 \\
\hline & $49-52$ years & 9 & 25.7 \\
\hline & 53-56 years & 13 & 37.1 \\
\hline & $57-60$ years & 3 & 8.6 \\
\hline \multirow[t]{2}{*}{ Gender } & Male & 13 & 37.1 \\
\hline & Female & 22 & 62.9 \\
\hline \multirow[t]{4}{*}{ Education } & Illiterate & 17 & 48.6 \\
\hline & $\begin{array}{l}\text { Primary } \\
\text { education }\end{array}$ & 11 & 31.4 \\
\hline & $\begin{array}{l}\text { Secondary } \\
\text { education }\end{array}$ & 2 & 5.7 \\
\hline & Graduation & 5 & 14.3 \\
\hline \multirow{4}{*}{ Occupation } & Govt employee & - & - \\
\hline & $\begin{array}{c}\text { Private } \\
\text { employee }\end{array}$ & 5 & 14.3 \\
\hline & Labor & 21 & 60 \\
\hline & Housewife & 9 & 25.7 \\
\hline \multirow{2}{*}{$\begin{array}{l}\text { Type of } \\
\text { family }\end{array}$} & Nuclear family & 20 & 57.1 \\
\hline & Joint family & 15 & 42.9 \\
\hline \multirow{4}{*}{$\begin{array}{l}\text { Health } \\
\text { Status }\end{array}$} & Excellent & 1 & 2.9 \\
\hline & Good & 22 & 62.9 \\
\hline & Average & 11 & 31.4 \\
\hline & Poor & 1 & 2.9 \\
\hline
\end{tabular}

Table 1: Shows that out of 35 middle aged adults, $28.6 \%$ were of $45-48$ years age group, $25.7 \%$ were of $49-52$ years age group, $37.1 \%$ were of $53-56$ years age group, $8.6 \%$ were $57-60$ years age group. Regarding gender, $37.1 \%$ were male and $62.9 \%$ were female. Regarding 
education, $48.6 \%$ were illiterate, $31.4 \%$ have primary education, $5.7 \%$ have secondary education, $14.3 \%$ have graduation. Regarding occupation, $14.3 \%$ were private employee, $60 \%$ were labour, $25.7 \%$ were housewife. Regarding type of family, 57.1\% are of nuclear family, $42.9 \%$ are of joint family. Regarding health status, $2.9 \%$ was excellent, $62.9 \%$ was good, $31.4 \%$ was average, $2.9 \%$ was poor.

\section{SECTION-II}

Table 2. Frequency and percentage distribution of level of social media exposure among middle aged adults $(\mathrm{n}=35)$

\begin{tabular}{|l|l|l|}
\hline $\begin{array}{l}\text { Level of social media } \\
\text { exposure }\end{array}$ & Frequency(f) & Percentage (\%) \\
\hline Below Average & Nil & Nil \\
\hline Average & 32 & $91.4 \%$ \\
\hline Above Average & 3 & $8.6 \%$ \\
\hline
\end{tabular}

Table 2: Shows that out of 35 sample, $91.4 \%$ had average and $8.6 \%$ had above average social media exposure with a mean and standard deviation of $31.9 \pm 3.03$.

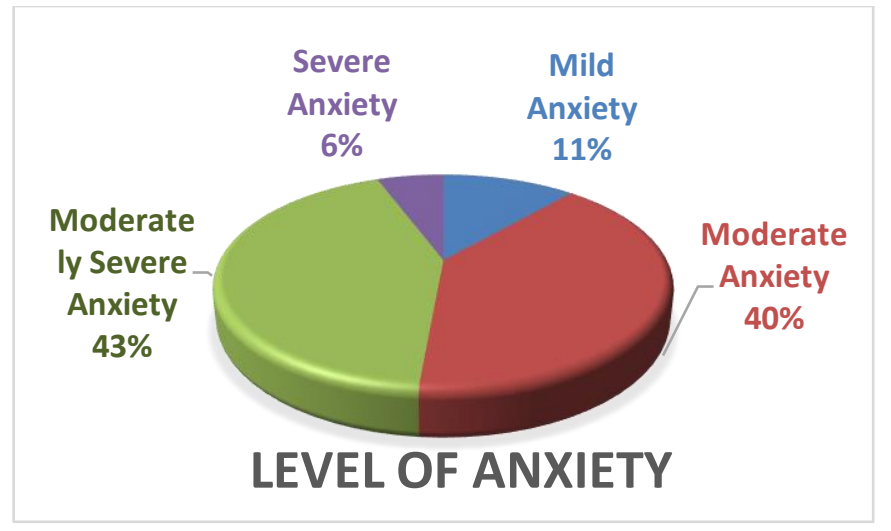

Figure 1: Frequency and percentage distribution of level of anxiety among middle aged adults. $(n=35)$

Figure 1: Shows that out of 35 sample, $11.4 \%$ had mild anxiety, $40 \%$ had moderate anxiety, $42.9 \%$ had moderate severe anxiety and $5.7 \%$ severe anxiety with a mean and standard deviation of $10.2 \pm 3.54$.

\section{SECTION-III}

Table-3 Correlation between level of social media exposure and anxiety among middle aged adults $(\mathrm{n}=35)$

\begin{tabular}{|l|c|l|}
\hline Variables & $\begin{array}{l}\text { Correlation } \\
\text { coefficient }\end{array}$ & Significance \\
\hline $\begin{array}{l}\text { Social media } \\
\text { exposure of }\end{array}$ & 0.20 & Positive Correlation \\
\hline $\begin{array}{l}\text { Level } \\
\text { anxiety }\end{array}$ & & \\
\hline
\end{tabular}

Table 3 : Shows that, there is moderate positive correlation (0.20) between the social media exposure and level of anxiety among middle aged adults. 


\section{SECTION-IV}

Table 4: Correlations: Demographic Variables Vs Anxiety and Social Media Exposure

\begin{tabular}{|l|c|c|c|c|}
\hline $\mathrm{n}=35$ & Anxiety & P Value & $\begin{array}{c}\text { Social Media } \\
\text { Exposure }\end{array}$ & P Value \\
\hline Age & 0.075 & 0.67 & 0.033 & $0 . .851$ \\
\hline Gender & -0.017 & 0.922 & 0.04 & 0.818 \\
\hline Education & -0.231 & 0.183 & -0.1 & 0.568 \\
\hline Occupation & 0.261 & 0.13 & 0.194 & 0.263 \\
\hline Type of family & 0.042 & 0.811 & 0.126 & 0.47 \\
\hline Health Status & 0.225 & 0.193 & 0.302 & 0.077 \\
\hline $\begin{array}{l}\text { Social media } \\
\text { exposure }\end{array}$ & 0.186 & 0.186 & & 1 \\
\hline Anxiety & 1 & 1 & 0.186 & 0.285 \\
\hline
\end{tabular}

Table 4: Shows that, there is positive correlation between anxiety and age, occupation, type of family, health status and negative relation with gender and education. Social media exposure has positive relation with age, gender, occupation, type of family, health status whereas education is in negative relation and there is no significance.

There is statistically significant association between the level of social media exposure and anxiety with health status at 0.05 level.

\section{DISCUSSION}

The first objective of the study was to assess the levels of anxiety and social media exposure during COVID outbreak among middle aged adults. Among 35 middle aged adults, $91.4 \%$ had average and $8.6 \%$ had above average social media exposure. $11.4 \%$ had mild anxiety, $40 \%$ had moderate anxiety, $42.9 \%$ had moderate severe anxiety and $5.7 \%$ severe anxiety. The present study supported by Junling Gao (2020) where the findings revealed that the prevalence of anxiety was $22.6 \%$ and more than $80 \%$ of participants reported above average exposure to social media during COVID outbreak in Wuhan, China. ${ }^{3}$ The second objective of the study was to assess the correlation between levels of anxiety and social media exposure during COVID outbreak among middle aged adults. The study revealed that the correlation coefficient value 0.20 and have moderate positive correlation. Mean and standard deviation of social media exposure are $31.9 \pm 3.03$ and of level of anxiety is $10.2 \pm 3.54$. The present study supported by Alasousi $\mathrm{L}$ where the findings revealed that there is positive correlation between media exposure and anxiety 
during COVID-19 outbreak in Kuwait $(\mathrm{p}<0.001)$, furthermore it revealed that there is significant relationship between the frequency of exposure and anxiety $(\mathrm{p}<0.001)^{6}$ The third objective of the study was to associate the levels of anxiety and social media exposure with selected demographic variables during COVID outbreak among middle aged adults. The study reveals there is significant association between the health status and the social media exposure with 0.011 probability $\left(\chi^{2}=11.219\right)$. And even there is significant association between the health status and the level of anxiety with 0.011 probability $\left(\chi^{2}=\right.$ 21.390) at 0.05 level of significance. The present study supported by Ebrahim AH where the findings revealed that the frequency of exposure to COVID-19 information was significantly associated with GAD (r $[304]=0.25, \mathrm{p}<0.001) .75 \%$ of participants were satisfied with the current possibilities of acquiring COVID-19 information. ${ }^{7}$

\section{v. CONCLUSION}

This study concludes that out of 35, 15(42.90\%) had moderate anxiety and $91.40 \%$ (32) had average social media exposure. Mean and standard deviation of social media exposure are $31.9 \pm 3.03$ and of level of anxiety is $10.2 \pm 3.54$. In relation to the findings most of the middle-aged adults had anxiety associated with the social media exposure. Conducting mental health camps to assess the mental health of an individual need for organizing health education session, volunteering, helping, supporting regarding level of anxiety during COVID outbreak and social media exposure is needed by nurses because their field of work is related to humanity that helps the individuals who had health problems in community level. Awareness programmes should be conducted to the public regarding the impact of social media among middle aged adults during COVID outbreak on mental health and prevention of mental health disorders.

\section{REFERENCES}

[1]. World Health Organization. Coronavirus disease 2019 (COVID-19) Pandemic. [cited 29 April 2020]. Available from : https://www.who.int/emergencies/diseases/nov el coronavirus- 2019.

[2]. Organization WH. Coronavirus disease 2019 (COVID19) Situation report 76. 2020.

[3]. Gao J, Zheng P, Jia Y, Chen H, Mao Y, et al. (2020) Mental health problems and social media exposure during COVID-19 outbreak. PLOS ONE 15(4): e0231924.

[4]. Denise F. Polit, Cheryl Tatano - A Text book of Nursing research, generating and assessing evidence for nursing practice, 8th edition, Lippincott Williams and Wilkins company, Wolter Kluwer publications, New Delhi, pg.no: 272-273. 59. 
[5]. Suresh K. Sharma- A text book of Nursing Cite this article as : K. Sudha Blessy, T. N. Prasanna research and statistics, 1st edition, Indian Lakshmi, Dr. M. Bhagya Lakshmi, Dr. S. Hemalatha, Elsevier publications, pg.no: 204-20

"A correlational study to assess the Level of Anxiety

[6]. Alasousi, Lulua Falah A Alhammouri, Sara A and Social Media Exposure during COVID Outbreak Alabdulhadi, Sara $\mathrm{T}$ Anxiety and media Among Middle Aged Adults in Selected Area at exposure during COVID-19 outbreak in Kuwait Tirupati", International Journal of Scientific Research D 2020 10.1101/2020.08.24.20180745 medRxiv 2020.08.24.20180745 in Science and Technology (IJSRST), Online ISSN : 2395-602X, Print ISSN : 2395-6011, Volume 8 Issue 1,

[7]. Ebrahim AH, Saif ZQ, Buheji M, AlBasri N, Alpp. 121-128, January-February 2021. Available at doi Husaini FA, Jahrami H (2020) COVID-19 : https://doi.org/10.32628/IJSRST218117 Information-Seeking Behavior and Anxiety Journal URL : http://ijsrst.com/IJSRST218117 Symptoms among Parents. OSP J Health Car Med 1. HCM-1-105

[8]. Jiang Hj, Nan J, Lv Zy, Yang J. Psychological impacts of the COVID-19 epidemic on Chinese people: Exposure, post-traumatic stress symptom, and emotion regulation. Asian Pac J Trop Med 2020;13: 252-9 